\title{
STRATEGI PENGEMBANGAN AGROINDUSTRI MANISAN MANGGA (Studi Kasus pada UMKM Satria di Kecamatan Kedawung, Kabupaten Cirebon)
}

\author{
${ }^{1}$ Josua Yeremia Thomas Gultom, ${ }^{2}$ Lies Sulistyowati \\ ${ }^{1}$ Mahasiswa Program Studi Agribsinis Fakultas Pertanian Universitas Padjadjaran \\ ${ }^{2}$ Dosen Program Studi Agribisnis Fakultas Pertanian Universitas Padjadjaran \\ ${ }^{1}$ Email: josuayeremia@yahoo.co.id
}

\begin{abstract}
ABSTRAK
Sektor agroindustri dan Usaha Mikro, Kecil dan Menengah (UMKM) menjadi kolaborasi strategis yang berperan penting dalam pembangunan ekonomi nasional maupun daerah. Penelitian ini bertujuan untuk merumuskan strategi pengembangan agroindustri pada UMKM Satria yang merupakan salah satu pelaku pengolahan manisan mangga di Kabupaten Cirebon.Penelitian ini menggunakan desain penelitian kualitatif dan teknik studi kasus dengan analisis SWOT.Hasil penelitian ini menunjukan bahwa strategi pengembangan agroindustri manisan mangga pada UMKM Satria yang dapat dilakukan yaitu: mempertahankan sistem manajemen bahan baku, mempertahankan pangsa pasar dan penjualan, dan meminimalisasi resiko serta menetapkan harga yang kompetitif. Hal tersebut dapat dilakukan dengan cara perawatan fasilitas produksi, meningkatkan konsistensi produk baik kualitas maupun kuantitas dan merencanakan volume produksi optimal.
\end{abstract}

Kata Kunci: Strategi Pengembangan, Agroindustri, UMKM

\begin{abstract}
Agro-industry and Micro, Small and Medium Enterprises (UMKM) become strategic collaborations that play an important role in national and regional economic development. This research aims to formulate the strategy of agroindustry development on UMKM Satria which is one of the processing actors of mango candied in Cirebon regency. This research uses qualitative research design and case study techniques with SWOT analysis. The results of this study indicate that the strategy of developing candied mango agroindustry in UMKM Satria can be done, namely: maintaining raw material management system, maintaining market share and selling, and minimizing risk and establishing competitive price. This can be done by maintenance of production facilities, improving product consistency both quality and quantity and planning optimal production volume.
\end{abstract}

Keywords: Development Strategy, Agro-industry, UMKM 


\section{PENDAHULUAN}

Agroindustri merupakan suatu rangkaian kegiatan industri yang terdiri dari proses produksi, pengolahan, pengangkutan, penyimpanan, pendanaan, pemasaran dan distribusi berbasis produk pertanian (Kurniati, 2015). Dapat dikatakan bahwa agroindustri adalah industri yang mengolah hasil pertanian menjadi bahan setengah jadi atau produk akhir yang melibatkan manusia, komoditas pertanian, modal, teknologi, informasi dan faktor-faktor lainnya. Keberadaan agroindustri sangat penting bagi kemajuan dan kesejahteraan suatu daerah. Dengan pertanian sebagai intinya, agroindustri mampu menyerap banyak tenaga kerja, meningkatkan pendapatan pelakunya, meningkatkan pendapatan daerah dan mampu memunculkan inovasi-inovasi terbaru sehingga menguatkan daya saing.

Kabupaten Cirebon merupakan salah satu daerah yang terletak di Provinsi Jawa Barat yang memiliki potensi industri pengolahan yang sangat besar, sehingga daerah ini terkenal sebagai daerah pusat oleh-oleh. Menurut data Badan Pusat Statistik Kabupaten Cirebon (2012-2016), sektor industri pengolahan menjadi sektor dengan kontribusi terbesar yaitu lebih dari $21 \%$ dari total pendapatan daerah.

Mangga adalah salah satu komoditas unggulan dan menjadi sumber penghidupan bagi masyarakat Provinsi Jawa Barat. Kabupaten Cirebon menempati urutan ketiga produksi mangga terbesar di Jawa Barat setelah Kabupaten Indramayu dan Kabupaten Majalengka (BPS Jawa Barat 2017).

Kabupaten Cirebon memiliki potensi sebagai sentra agroindustri pengolahan buah-buahan terutama mangga. Manisan mangga merupakan salah satu produk olahan khas daerah yang terkenal di daerah Cirebon.Salah satu UMKM pengolah manisan manggadi Kabupaten Cirebon adalah UMKM Satria yang sudah memulai usaha sejak tahun 1983.

Menurut Udayana (2011), strategi pengembangan agroindustri harus disesuaikan dengan permasalahan yang dihadapi oleh agroindustri bersangkutan. Permasalahan tersebut antara lain yaitu: (a) karakteristik produk pertanian yang mudah rusak (perishable); (b) tidak terjaminnya kontinunitas bahan baku, sebagian besar produk pertanian yang sifatnya musiman karena ketersediaannya tergantung faktor iklim; (c) kualitas produk pertanian dan agroindustri masih 
belum terstandar sehingga sulit bersaing; (d) agroindustri berskala UMKM masih minim modal dan teknologi.Selain itu, terdapat tantangan persaingan agroindustri manisan mangga antarusaha baik dengan jenis usaha sejenis maupun berbeda jenis.

Berdasarkan latar belakang dan tantangan tersebut, berdasarkan faktorfaktor internal dan eksternal dibutuhkan strategi pengembangan agroindustri bagi UMKM Satria agar dapat meningkatkan daya saing. Strategi tersebut dirancang untuk mengatasi permasalahan yang menghambat pengembangan agroindustri manisan mangga dengan cara mengurangi kelemahan dan ancaman. Kemudian dibentuk strategi untuk menciptakan dan memanfaatkan segala peluang dan kekuatan yang sudah dimiliki.

Diharapkan agroindustri manisan mangga di UMKM Satria dapat semakin berkembang dan bersaing dengan daerah lain bahkan dengan produk di pasar internasional.

\section{TINJAUAN PUSTAKA}

Agroindustri dikenal sebagai kegiatan industri yang mengolah hasil pertanian sebagai bahan baku menjadi produk akhir atau barang setengah jadi, serta menyediakan peralatan dan jasa untuk mendukung kegiatan tersebut. Namun, agroindustri lebih dikenal sebagai industri hilir yang mengolah dan menghasilkan barang siap konsumsi.

$$
\text { Menurut Austin }
$$
agroindustri merupakan perusahaan yang melakukan pengolahan secara fisik maupun kimiawi terhadap bahan baku yang berasal dari tanaman dan hewan dengan sehingga tercipta perubahan bentuk dan peningkatan masa simpan produk.

Hicks (1995) dalam Tarigan dan Ariningsih (2007) mengemukakan bahwa ciri-ciri kegiatan agroindustri yaitu: (a) meningkatkan nilai tambah, (b) menghasilkan produk yang bermanfaat dan dapat dipasarkan, (c) meningkatkan daya simpan, (d) menghasilkan keuntungan pendapatan bagi produsen.

Berdasarkan UU No. 20 Tahun 2008 tentang Usaha Mikro, Kecil dan Menengah (UMKM), kriteria yang termasuk ke dalam UMKM adalah sebagai berikut:

a. Kriteria Usaha Mikro yaitu memiliki kekayaan bersih paling banyak Rp. 50.000.000,00 (lima puluh juta rupiah) tidak termasuk tanah dan bangunan tempat usaha; atau memiliki hasil penjualan tahunan 
paling banyak Rp. 300.000.000,00 (tiga ratus juta rupiah).

b. Kriteria Usaha Kecil yaitu memiliki kekayaan bersih lebih dari Rp. 50.000.000,00 (lima puluh juta rupiah) sampai dengan paling banyak Rp. 500.000.000,00 (lima ratus juta rupiah) tidak termasuk tanah dan bangunan tempat usaha; atau memiliki hasil penjualan tahunan lebih dari Rp. 300.000.000,00 (tiga ratus juta rupiah) sampai dengan paling banyak Rp. 2.500.000.000,00 (dua miliyar lima ratus juta rupiah).

c. Kriteria Usaha Menengah yaitu memiliki kekayaan bersih lebih dari Rp. 500.000.000,00 (lima ratus juta rupiah) sampai dengan paling banyak Rp. 10.000.000.000,00 (sepuluh miliyar rupiah) tidak termasuk tanah dan bangunan tempat usaha; atau memiliki hasil penjualan tahunan lebih dari Rp. 2.500.000.000,00 (dua miliyar lima ratus juta rupiah) sampai dengan paling banyak Rp. 50.000.000.000,00 (lima puluh milyar rupiah).

Menurut Simatupang (1997), strategi didefinisikan sebagai suatu konsep dan rancangan yang menghasilkan keterpaduan antara tujuan, kebijakan dan tindakan organisasi secara menyeluruh. Sedangkan pengertian dari pengembangan agroindustri adalah segala upaya yang dilakukan agar tercipta kinerja lebih baik dari sebelumnya.

Menurut Rangkuti (1998), analisis SWOT adalah cara perusahaan atau organisasi untuk mengidentifikasi berbagai faktor secara sistematis untuk merumuskan strategi yang paling tepat dilakukan untuk mencapai tujuan. Analisis SWOT merupakan langkah penting dalam merumuskan startegi dengan mengukur kekuatan (strengths) dan kelemahan (weakness) yang berasal dari lingkungan internal perusahaan termasuk juga kinerja perusahaan, demikian juga kesempatan (opportunities) dan ancaman (threats) yang berasal dari lingkungan luar atau eksternal perusahaan.

\section{METODOLOGI PENELITIAN}

Objek yang dikaji dan diteliti dalam penelitian ini adalah strategi pengembangan agroindustri manisan mangga pada salah satu UMKM di Kabupaten Cirebon. Penelitian ini dilakukan di UMKM Satria yang terletak di Jl. Sultan Ageng Tirtayasa, Gg. Mandiri No. 09, RT. 01/RW. 01, Desa Kedungjaya, Kecamatan Kedawung. 
Desain penelitian ini adalah penelitian kualitatif. Menurut Sugiyono (2010), metode penelitian kualitatif merupakan metode penelitian yang berlandaskan pada filsafat positivisme, digunakan untuk meneliti pada kondisi obyek yang alamiah, (lawannya adalah eksperimen) dimana peneliti adalah sebagai instrumen utama. Metode yang digunakan adalah studi kasus.

Pengambilan data dan penentuan informan dilakukan secara sengaja (purposive), teknik pengumpulan data dengan triangulasi, analisis data bersifat induktif/kualitatif, dan hasil penelitian kualitatif lebih menekan makna daripada generalisasi.

Teknik analisis data pada penelitian ini adalah analisis deskriptif dan analisis SWOT untuk merumuskan strategi pengembangan agroindustri manisan mangga UMKM Satria.

\section{HASIL DAN PEMBAHASAN}

Faktor yang Mempengaruhi Strategi Pengembangan Agroindustri Manisan Mangga di UMKM Satria:

Faktor Internal (Kekuatan dan Kelemahan)

Terdapat beberapa faktor internal yang diidentifikasi menjadi kekuatan agroindustri manisan mangga di UMKM
Satria, yaitu:1) Manajemen persediaan bahan baku yang baik, 2) Selalu tersedianya tenaga kerja kupas potong, 3) Tersedianya modal untuk menjalankan usaha, 4) Memiliki ruang khusus untuk pengolahan, 5) Memiliki rumah kaca untuk tahap pengeringan, 6) Sudah menerapkan Good Manufacturing Practices (GMP), 7) Memperhatikan batas penggunaan pengawet dan pewarna, 8) Memiliki sertifikat P-IRT dan Halal, 9) Inovasi kemasan yang menarik, 10) Variasi produk manisan, 11) Memiliki Surat Keterangan Usaha (SKU), dan 12) Lokasi tempat usaha yang strategis.

Setelah diidentifikasi, juga terdapat faktor internal yang menjadi kelemahan agroindustri manisan mangga di UMKM Satria, yaitu: 1)Kurangnya ketersediaan kapasitas bangunan, 2) Peralatan masih tergolong sederhana, 3) Sistem pembukuan masih tradisional, 4) Pengelolaan keuangan usaha belum terpisah, 5) Belum memiliki SPO tertulis, 6) Belum memiliki standarisasi produk yang baku, 7) Harga tergolong cukup mahal, 8) Belum memiliki toko khusus untuk pemasaran, 9) Belum ada promosi langsung (onlinelface to face), dan 10) Belum ada regenerasi pengelola.

Faktor Eksternal (Peluang dan Ancaman) 
Terdapat beberapa faktor eksternal yang diidentifikasi menjadi peluang agroindustri manisan mangga di UMKM Satria, yaitu: 1) Mangga adalah tanaman musiman, 2) Iklim di daerah Cirebon yang mendukung tahap pengeringan, 3) Kebijakan pemerintah yang memperhatikan UMKM, 4) Program pemerintah dalam pengembangan UMKM, 5) Program Kredit Tanpa Bunga (KTB) dan Kredit Tanpa Agunan (KTA), 6) Keberadaan Masyarakat Klaster Pengolahan Buah (Masterbu), 7) Hari Raya setiap tahun yang meningkatkan pendapatan, 8) Tersedianya bahan baku di daerah Cirebon, 9) Hubungan yang baik dengan pemasok bahan baku, 10) Pesaing tidak melakukan produksi secara kontinu, 11) Presepsi konsumen terhadap produk yang baik, 12) Kemajuan teknologi komunikasi dan informasi, 13) Tersedianya pasar ekspor, dan 14) Tersedianya layanan jasa pengiriman atau ekspedisi.

Setelah diidentifikasi, juga terdapat faktor eksternal yang menjadi ancaman agroindustri manisan mangga di UMKM Satria, yaitu: 1) Teknologi offseason, 2) Musim hujan menghambat tahap pengeringan, 3) Bantuan dari pemerintah kadang tidak tepat sasaran, 4) Kenaikan harga-harga kebutuhan pokok,
5) Harga bahan baku yang diperoleh masih terbilang mahal, 6) Muncul pesaing-pesaing baru dengan produk sejenis, 7) Harga produk pesaing yang lebih murah, dan 8) Sistem pasar modern yang tidak menguntungkan.

\section{Matriks Internal Factor Evaluation (IFE) dan External Factor Evaluation (EFE)}

Tabel 1 menunjukan bahwa nilai tertinggi untuk faktor internal yang paling berpengaruh sebagaikekuatanutama adalah manajemen persediaan bahan baku yang baik $(0,24)$, memperhatikan batas penggunaan pengawet dan pewarna $(0,24)$, dan memiliki sertifikat P-IRT dan Halal $(0,24)$.

Tabel 2 menunjukan bahwa nilai tertinggi untuk faktor eksternal yang berpotensi sebagai peluang utama adalah Mangga adalah tanaman musiman $(0,24)$, Hari Raya setiap tahun yang meningkatkan pendapatan $(0,24)$, tersedianya bahan baku di daerah Cirebon $(0,24)$, dan presepsi konsumen terhadap produk yang baik $(0,24)$.

Tabel 1 dan Tabel 2 dapat dilihat sebagai berikut: 


\section{Matriks Internal Factor Evaluation (IFE)}

Tabel 1. Identifikasi Faktor Internal Agroindustri Manisan Mangga UMKM Satria

\begin{tabular}{|c|c|c|c|}
\hline Faktor Strategis Internal & Bobot & Rating & Skor \\
\hline \multicolumn{4}{|l|}{ Kekuatan: } \\
\hline 1. Manajemen persediaan bahan baku yang baik & 0,06 & 4 & 0,24 \\
\hline 2. Selalu tersedianya tenaga kerja kupas potong & 0,04 & 3 & 0,12 \\
\hline 3. Tersedianya modal untuk menjalankan usaha & 0,06 & 3 & 0,18 \\
\hline 4. Memiliki ruang khusus untuk pengolahan & 0,04 & 3 & 0,12 \\
\hline 5. Memiliki rumah kaca untuk tahap pengeringan & 0,05 & 4 & 0,20 \\
\hline $\begin{array}{l}\text { Sudah menerapkan Good Manufacturing } \\
\text { Practices (GMP) }\end{array}$ & 0,05 & 4 & 0,20 \\
\hline $\begin{array}{l}\text { 7. Memperhatikan batas penggunaan pengawet dan } \\
\text { pewarna }\end{array}$ & 0,06 & 4 & 0,24 \\
\hline 8. Memiliki sertifikat P-IRT dan Halal & 0,06 & 4 & 0,24 \\
\hline 9. Inovasi kemasan yang menarik & 0,04 & 4 & 0,16 \\
\hline 10 Variasi produk manisan & 0,04 & 3 & 0,12 \\
\hline 11. Memiliki Surat Keterangan Usaha (SKU) & 0,03 & 3 & 0,09 \\
\hline 12. Lokasi tempat usaha yang strategis & 0,03 & 3 & 0,09 \\
\hline \multicolumn{4}{|l|}{ Kelemahan: } \\
\hline 1. Kurangnya ketersediaan kapasitas bangunan & 0,06 & 1 & 0,06 \\
\hline 2. Peralatan masih tergolong sederhana & 0,03 & 2 & 0,06 \\
\hline 3. Sistem pembukuan masih tradisional & 0,03 & 2 & 0,06 \\
\hline $\begin{array}{l}\text { Pengelolaan keuangan usaha belum terpisah } \\
\text { dengan rumah tangga }\end{array}$ & 0,03 & 2 & 0,06 \\
\hline 5. Belum memiliki SPO tertulis & 0,04 & 2 & 0,08 \\
\hline 6. Belum memiliki standarisasi produk yang baku & 0,05 & 1 & 0,05 \\
\hline 7. Harga tergolong cukup mahal & 0,04 & 1 & 0,04 \\
\hline 8. Belum memiliki toko khusus untuk pemasaran & 0,04 & 2 & 0,08 \\
\hline 9. Belum ada promosi langsung (onlinelface to face) & 0,06 & 1 & 0,06 \\
\hline 10. Belum ada regenerasi pengelola & 0,06 & 1 & 0,06 \\
\hline TOTAL & 1,00 & & 2,61 \\
\hline
\end{tabular}

Tabel 1 menunjukan bahwa nilai tertinggi untuk faktor internal yang paling berpengaruh sebagai kelemahan utama adalah belum memiliki SPO tertulis $(0,08)$ dan belum memiliki toko khusus untuk pemasaran (0,08). Sedangkan kelemahan terkecil yang dimiliki adalah harga produk yang tergolong cukup mahal $(0,04)$. 


\section{Matriks Eksternal Factor Evaluation (EFE)}

Tabel 2. Identifikasi Faktor Eksternal Agroindustri Manisan Mangga UMKM Satria

\begin{tabular}{|c|c|c|c|}
\hline Faktor Strategis Eksternal & Bobot & Rating & Skor \\
\hline \multicolumn{4}{|l|}{ Peluang: } \\
\hline 1. Mangga adalah tanaman musiman & 0,06 & 4 & 0,24 \\
\hline $\begin{array}{l}\text { 2. Iklim di daerah Cirebon yang mendukung tahap } \\
\text { pengeringan }\end{array}$ & 0,04 & 4 & 0,16 \\
\hline $\begin{array}{l}\text { 3. Kebijakan pemerintah yang memperhatikan } \\
\text { UMKM }\end{array}$ & 0,05 & 3 & 0,15 \\
\hline 4. Program pemerintah dalam pengembangan UMKM & 0,06 & 3 & 0,18 \\
\hline $\begin{array}{l}\text { Program Kredit Tanpa Bunga (KTB) dan Kredit } \\
\text { Tanpa Agunan (KTA) }\end{array}$ & 0,04 & 4 & 0,16 \\
\hline $\begin{array}{l}\text { Keberadaan Masyarakat Klaster Pengolahan Buah } \\
\text { (Masterbu) }\end{array}$ & 0,03 & 3 & 0,09 \\
\hline $\begin{array}{l}\text { 7. Hari Raya setiap tahun yang meningkatkan } \\
\text { pendapatan }\end{array}$ & 0,06 & 4 & 0,24 \\
\hline 8. Tersedianya bahan baku di daerah Cirebon & 0,06 & 4 & 0,24 \\
\hline 9. Hubungan yang baik dengan pemasok bahan baku & 0,04 & 3 & 0,12 \\
\hline 10. Pesaing tidak melakukan produksi secara kontinu & 0,05 & 4 & 0,20 \\
\hline 11. Presepsi konsumen terhadap produk yang baik & 0,06 & 4 & 0,24 \\
\hline 12. Kemajuan teknologi komunikasi dan informasi & 0,03 & 3 & 0,09 \\
\hline 13. Tersedianya pasar ekspor & 0,03 & 3 & 0,09 \\
\hline 14. Tersedianya layanan jasa pengiriman atau ekspedisi & 0,04 & 3 & 0,12 \\
\hline \multicolumn{4}{|l|}{ Ancaman: } \\
\hline 1. Teknologi off-season & 0,04 & 1 & 0,04 \\
\hline 2. Musim hujan menghambat tahap pengeringan & 0,03 & 2 & 0,06 \\
\hline 3. Bantuan dari pemerintah kadang tidak tepat sasaran & 0,03 & 2 & 0,06 \\
\hline 4. Kenaikan harga-harga kebutuhan pokok & 0,06 & 1 & 0,06 \\
\hline $\begin{array}{l}\text { 5. Harga bahan baku yang diperoleh masih terbilang } \\
\text { mahal }\end{array}$ & 0,06 & 1 & 0,06 \\
\hline $\begin{array}{l}\text { Muncul pesaing-pesaing baru dengan produk } \\
\text { sejenis }\end{array}$ & 0,06 & 1 & 0,06 \\
\hline 7. Harga produk pesaing yang lebih murah & 0,01 & 1 & 0,01 \\
\hline 8. Sistem pasar modern yang tidak menguntungkan & 0,06 & 2 & 0,06 \\
\hline TOTAL & $\mathbf{1 , 0 0}$ & & 2,74 \\
\hline
\end{tabular}

Tabel 2 menunjukan bahwa nilai tertinggi untuk faktor eksternal yang paling berpotensi sebagai acaman utama adalahMusim hujan menghambat tahap pengeringan $(0,06)$, Bantuan dari pemerintah kadang tidak tepat sasaran $(0,06), \quad$ Kenaikan harga-harga kebutuhan pokok $(0,06)$, Harga bahan baku yang diperoleh masih terbilang mahal $(0,06)$, Muncul pesaing-pesaing baru dengan produk sejenis, dan Sistem pasar modern yang tidak menguntungkan 
$(0,06)$. Sedangkan ancaman terlemah yang dihadapi adalah Harga produk

\section{Analisis Matriks Internal-Eksternal (IE)}

Matriks IE (Internal-Eksternal) dihasilkan melalui pencocokan informasi yang diperoleh dari tabel Matriks EFE dan IFE untuk mendapatkan informasi mengenai posisi perusahaan guna mempermudah dalam menentukan alternatif strategi.Nilai matriks IFE sebesar 2,61 menunjukkan bahwaagroindustri manisan mangga UMKM Satria memiliki kemampuan yang cukup baik dalam memanfaatkan kekuatan dan mengatasikelemahan yang dimiliki. Sedangkan nilai matriks EFE sebesar 2,74 menunjukkan bahwa agroindustri manisan mangga UMKM Satriamemiliki kemampuan yang cukup baik dalam memanfaatkan peluang dan menghindari ancaman.

Berdasarkan nilai matriks IFE dan EFE tersebut, didapatkan bahwa posisi potensi pengembangan agroindustri manisan mangga UMKM Satria ada pada sel V. Menurut David (2006), sel ini menunjukan jenis strategi yang cocok untuk diterapkan adalah "Hold and Maintain". Berdasarkan jenis tersebut, strategi yang dapat dilakukan untuk agroindustri manisan mangga Kelompok pesaing yang lebih murah $(0,01)$.

Satria yaitu: penetrasi pasar dan pengembangan produk. Penetrasi pasar merupakan strategi-strategi yang digunakan suatu perusahaan untuk fokus dalam mempertahankan atau meningkatkan pangsa pasar atau penjualan produk yang sudah terdapat di pasar. Strategi penetrasi pasar dapat dilakukan dengan penetapan harga yang kompetitif, upaya iklan atau promosi produk, menjalin kemitraan untuk pemasaran dan meraih loyalitas konsumen.

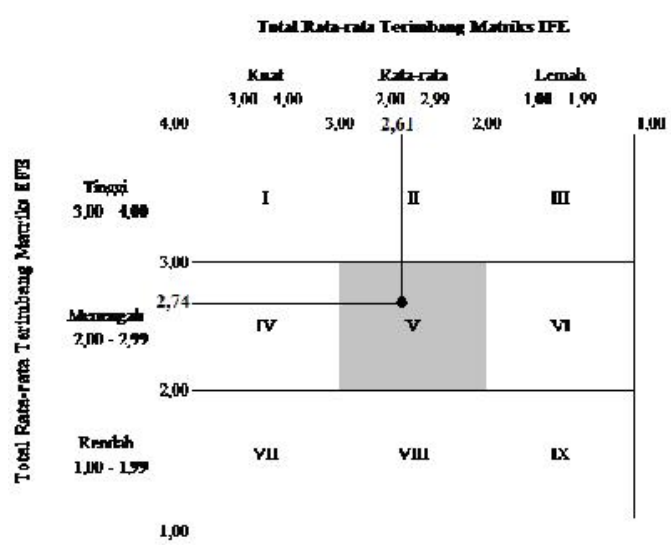

Gambar 1. Matriks IE Agroindustri Manisan Mangga UMKM Satria 


\section{Matriks Analisis SWOT}

Tabel 3. Matriks SWOT Strategi Pengembangan Agroindustri Manisan Mangga UMKM Satria

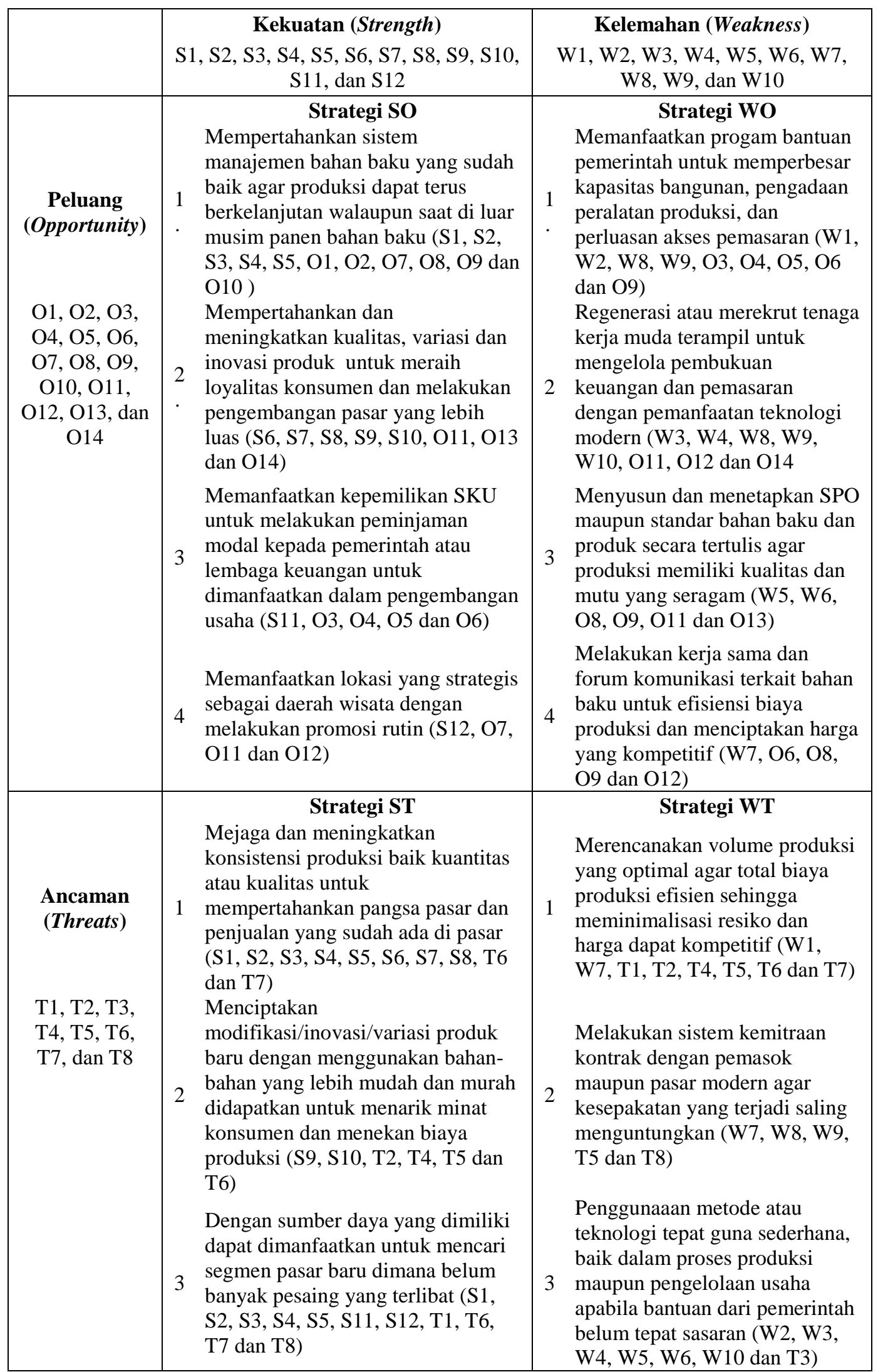


Setelah analisis faktor internal dan eksternal agroindustri manisan mangga Kelompok Satria dimasukan ke dalam Matriks IFE dan Matriks EFE, kemudian hasilnya dimasukkan dalam model kualitatif. Matriks SWOT sebagai model kualitatif digunakan sebagai acuan dalam merumuskan strategi kompetitif perusahaan. Matriks ini akan menghasilkan empat tipe alternatif strategi berdasarkan pencocokan antara setiap elemen SWOT yaitu: Kekuatan (SStrength), Kelemahan (W-Weakness), Peluang (O-Opportunity), dan Ancaman (T-Threats) yang dimiliki dan dihadapi UMKM Satria (Tabel 3).

\section{PENUTUP}

1. Identifikasi lingkungan internal dan eksternal agroindustri manisan mangga Kelompok Satria:
a. Kekuatan utama meliputi manajemen persediaan bahan baku yang baik, memiliki bangunan rumah kaca untuk tahap pengeringan dan sudah diterapkannya Good

Manufacturing Practices (GMP).

b. Kelemahan utama meliputi kekurangan ketersediaan kapasitas bangunan, belum memiliki strandar produk yang baku, harga jual tergolong cukup mahal dan belum melakukan promosi.

c. Peluang utama meliputi mangga yang merupakan tanaman musiman, iklim di daerah Cirebon yang mendukung tahap pengeringan, ketersediaan bahan baku di Cirebon dan pesaing yang tidak berproduksi secara kontinu.

d. Ancaman utama meliputi keberadaan teknologi off-season, kenaikan harga-harga kebutuhan pokok, harga bahan baku yang mahal, munculnya pesaingpesaing baru dengan produk sejenis, dan harga produk pesaing yang lebih murah

2. Strategi pengembangan yang tepat untuk diterapkan pada agroindustri manisan mangga Kelompok Satria adalah jenis strategi "Hold and Maintain". Strategi tersebut dapat dilakukan dengan cara menerapkan strategi prioritas yaitu mempertahankan sistem manajemen bahan baku yang sudah baik agar produksi dapat terus berkelanjutan walaupun saat di luar musim panen mangga sebagai bahan 
baku. Strategi selanjutnya yang dapat dilakukan adalah memanfaatkan kepemilikan SKU untuk melakukan peminjaman modal kepada pemerintah atau lembaga keuangan untuk dimanfaatkan dalam pengembangan usaha manisan mangga.

\section{DAFTAR PUSTAKA}

Austin J. E. 1992. Agroindustrial Project Analysis Critical Design Factors: EDI Series in Economic Development Second Edition. Baltimore: John Hopkins Univ. Press

BPS Kabupaten Cirebon. 2017. Kabupaten Cirebon Dalam Angka 2017. Badan Pusat Statistik Kabupaten Cirebon.

BPS Provinsi Jawa Barat. 2017. Jawa Barat Dalam Angka 2017. Badan Pusat Statistik Provinsi Jawa Barat. David, Fred. R. 2006. Manajemen StrategisEdisi Sepuluh. Jakarta: Penerbit Salemba Empat.

Kurniati, Edy Dwi. 2015. Kewirausahaan Industri. Yogyakarta: Penerbit Deepublish.
Rangkuti, F. 1998. Analisis SWOT Teknik

Membedah Kasus Bisnis. Jakarta: Gramedia Pustaka Utama.

Simatupang TM. 1997. Pemodelan Sistem. Bandung: Studio Manajemen Jurusan Teknik Industri. Bandung: Institut Teknologi Bandung.

Sugiyono. 2012. Metode Penelitian Pendidikan, Pendekatan Kuantitatif Kualitatif, dan $R \& D$. Bandung: Alfabeta.

Tarigan, H. dan E. Ariningsih 2007. Peluang dan Kendala Agroindustri Sagu di Kabupaten Jayapura. Pusat Analisis Sosial Ekonomi dan Kebijakan Pertanian. Bogor.

Udayana, I. G. B. 2011. "Peran Agroindustri dalam Pembangunan Pertanian". Jurnal Singhadwala, Edisi 44, Februari. 